\title{
Olea europaea Linn (Oleaceae) Fruit Pulp Extract Exhibits Potent Antioxidant Activity and Attenuates Neuroinflammatory Responses in Lipopolysaccharide- Stimulated Microglial Cells
}

\author{
Moo-Sung $\mathrm{Kim}^{2}$, Sushruta Koppula ${ }^{1}$, Seung-Hyo Jung ${ }^{1,3}$, Ji-Young $\mathrm{Kim}^{1,3}$, \\ Hyoung-Ro Lee ${ }^{1,4}$, Sang-Rin Lee ${ }^{2}$, Yong-Dae Park ${ }^{2}$, Kyung-Ae Lee ${ }^{2}$, Tae-Kyu \\ Park ${ }^{1}$ and Hyun Kang ${ }^{*}$ \\ ${ }^{1}$ Department of Biotechnology, Research Institute for Biomedical \& Health Science, College of Biomedical and Health Science, \\ Konkuk University, Chungju, 380-701, ${ }^{2} R \& D$ Center, Macrocare Tech, Ltd, Ochang, 363-883, ${ }^{3}$ KuGen Healthcare Institute, \\ Chungju, 380-150, ${ }^{4}$ Nutra MediPharm, Chungju, 380-701 Republic of Korea
}

*For correspondence: Email: hkang@kku.ac.kr; Tel: 82-43-840-3603; Fax: 82-43-852-3616;

Received: 26 March 2013

Revised accepted: 12 April 2013

\begin{abstract}
Purpose: To investigate the antioxidant and anti-neuroinflammatory potentials of Olea europaea Linn. fruit pulp (OFP-EA) extract in LPS-stimulated BV-2 microglial cells.

Methods: Cell viabilities were measured using 3-(4,5-dimethylthiazol-2-yl)-2,5- diphenyl-tetrazolium bromide (MTT) assay. Antioxidant properties were evaluated using 1, 1-diphenyl-2-picryl-hydrazyl $(D P P H)$ radical scavenging activity. Lipopolysaccharide (LPS) was used to stimulate BV-2 microglia. Nitric oxide (NO) production was measured using Griess assay. Inducible NO synthase (iNOS) expression and tumor necrosis factor-alpha (TNF- $\alpha$ ) production were measured using enzyme-linked immunosorbent assay (ELISA) and Western blot analysis.

Results: OFP-EA extract significantly $(p<0.001$ at $20-200 \mu \mathrm{g} / \mathrm{ml}$, respectively) scavenged the free radicals in a dose-dependent fashion. The increased levels of No stimulated by LPS (34 \pm 2.41$)$ were also inhibited by OFP-EA extract significantly and concentration dependently $(27 \pm 2.32,21 \pm 2.54$, $17 \pm 1.92$ and $11 \pm 1.94$ at $10,20,40$ and $80 \mu \mathrm{g} / \mathrm{ml}$, respectively). Further, OFP-EA suppressed the elevated levels iNOS expression and TNF- $\alpha$ production $(p<0.001$ at 20,40 and $80 \mu \mathrm{g} / \mathrm{ml})$ in LPSstimulated BV-2 cells.

Conclusion: Results indicate that OFP-EA extract exhibited strong antioxidant properties and inhibited the excessive production of pro-inflammatory mediators such as NO, iNOS and TNF- $\alpha$ in LPSstimulated BV-2 cells. The antioxidant activity exhibited by OFP-EA extract might play a critical role in ameliorating the inflammatory processes in LPS-stimulated BV-2 microglial cells.
\end{abstract}

Key words: Olive fruit pulp, antioxidant, neuroinflammation, microglia, TNF- $\alpha$, iNOS.

Tropical Journal of Pharmaceutical Research is indexed by Science Citation Index (SciSearch), Scopus, International Pharmaceutical Abstract, Chemical Abstracts, Embase, Index Copernicus, EBSCO, African Index Medicus, JournalSeek, Journal Citation Reports/Science Edition, Directory of Open Access Journals (DOAJ), African Journal Online, Bioline International, Open-J-Gate and Pharmacy Abstracts

\section{INTRODUCTION}

Microglial activation plays a pivotal role in neuroinflammation and is involved in the neuropathological changes seen in several central nervous system (CNS) diseases such as multiple sclerosis (MS), Parkinson's disease (PD), Alzheimer's disease (AD) and Huntington's disease $[1,2]$. Activation of microglia results in release of different pro-inflammatory mediators 
and free radicals [3]. It is well documented that reduction of pro-inflammatory mediators such as nitric oxide (NO), inducible NO synthase (iNOS), tumor necrosis factor-alpha (TNF-a) and other inflammatory cytokines in activated microglia could attenuate the severity of these disorders $[4,5]$. Lipopolysaccharide (LPS), found in the outer membrane of Gram-negative bacteria can stimulate microglia both in vitro and in vivo to release various pro-inflammatory and neurotoxic factors [2]. Therefore LPS-stimulated microglia is a useful in vitro model for rapid screening of several anti-neuroinflammatory agents [6]. Olea europaea Linn. (family, Oleaceae), commonly known as olive is among the oldest known cultivated trees in the world with immense medicinal values. Olives and its associated products have been used widely as folk medicines in Spain, Italy, France, Greece, Israel, Morocco, Tunisia, Turkey and the Mediterranean islands for centuries [7]. Today, the olive plant is most well known for its fruit crop and oil. As a folk remedy, olives have been used to reduce the incidence of heart diseases [8]. Experimental studies on the fruits and leaf extracts from olives show that they possess anti-thrombotic, antihypertensive, anti-cancer, hypoglycemic, antiinflammatory, anti-microbial and anti-atherogenic properties [9, 10]. The major active components of olives are phenolic constituents including oleuropein, hydroxytyrosol, tyrosol, 4hydroxyphenyl acetic acid, protocatechuic acid, caffeic acid and p-coumaric acid. However, several other biologically active constituents are also present $[8,11]$.

Although the health beneficial effects of olive fruit and leaf oils have been confirmed in vitro using different cell lines [10], studies on the olive fruit pulp extracts and their protective effect on neuroinflammatory conditions using microglial cells have not been demonstrated. In the present study the ethyl acetate fraction obtained from olive fruit pulp extract (OFP-EA) was investigated for its anti-neuroinflammatory effects in LPSstimulated BV-2 microglial cells and the antioxidant property was also evaluated to substantiate its anti-neuroinflammatory effects.

\section{EXPERIMENTAL}

\section{Preparation of the OFP-EA extract}

Green olive fruits collected at the end of September to about the middle of November were obtained from the local market, Seoul, South Korea. The collected fruit material was authenticated by Prof. Jong-Bo Kim, a taxonomist at Konkuk University, Korea and a voucher specimen (OL-KU2012) has been kept in our laboratory herbarium, Konkuk University,
Korea for future reference. To obtain the olive fruit pulp extract, $500 \mathrm{~g}$ of the fruit were ground in a mixer and defatted three times with three volumes of $80 \%$ ethanol. The residue (fruit pulp) was extracted with absolute ethanol $(\mathrm{EtOH})$ at $1: 10$ ratio $(\mathrm{w} / \mathrm{v})$ for $2 \mathrm{~h}$ in a heating mantle at 70 $80{ }^{\circ} \mathrm{C}$. The supernatant was filtered and concentrated in a rotatory evaporator at $50^{\circ} \mathrm{C}$. The ethanol extract of olive fruit pulp obtained $(180 \mathrm{~g})$ was re-suspended in water:EtOH (9:1, $\mathrm{v} / \mathrm{v}$ ) and partitioned successively with n-hexane, ethyl acetate (EA) and n-butanol to obtain a final yield of 19.4, 52 and $27.27 \%$, respectively. Since EA fraction of olive fruit pulp extract showed potent antioxidant effect in our preliminary evaluation, further studies on anti-neuroinflammatory effects in LPS-stimulated BV-2 microglial cells was investigated using OFP-EA extract. The extract was dissolved in sterile distilled water and filtered on $0.22 \mu \mathrm{m}$ filters before use. All reagents used in this study were of highest grade available commercially.

\section{DPPH radical scavenging activity}

The anti-oxidant activity of the OFP-EA extract was determined using the stable radical 2, 2diphenyl-1-picrylhydrazyl (DPPH, Sigma-Aldrich, St. Louis, MO, USA). The radical scavenging capacity was evaluated by employing a reaction mixture constituted by aliquots of the OFP-EA extract and a DPPH methanolic solution as described previously [12]. Briefly, a sample solution of $60 \mu \mathrm{l}$ of each OFP-EA extract, was added to $60 \mu \mathrm{l}$ of DPPH $(60 \mu \mathrm{M})$ in methanol. After mixing vigorously for $10 \mathrm{~s}$, the mixture was then transferred into a $100 \mu \mathrm{l}$ Teflon capillary tube and the scavenging activity of each sample on DPPH radical was measured using a JES-FA ESR spectrometer (Jeol Ltd, Tokyo, Japan). A spin adduct was measured on an ESR spectrometer exactly after 2 min. Experimental conditions were as follows: central field, 3,475 G; modulation frequency, $100 \mathrm{kHz}$; modulation amplitude, 2 G; microwave power, $5 \mathrm{~mW}$; gain, $6.3 \times 10^{5}$, and temperature, $298^{\circ} \mathrm{K}$.

\section{Cell culture and viability assay}

BV-2 microglia cells were cultured at $37^{\circ} \mathrm{C}$ in 5 $\% \mathrm{CO}_{2}$ in DMEM (Invitrogen, Carlsbad, CA, USA) supplemented with $5 \%$ FBS (Hyclone, Logan, UT, USA) and antibiotics (Invitrogen). In all experiments, cells were pre-treated with OFPEA $(10,20,40$ and $80 \mu \mathrm{g} / \mathrm{ml})$ for $1 \mathrm{~h}$ before the addition of LPS (1 $\mu \mathrm{g} / \mathrm{ml}$, Sigma-Aldrich, St Louis, MO, USA) in serum free DMEM. An equal volume of sterile water was added to all control treatments. 
For viability assay, 3-(4, 5-dimethylthiazol-2-yl)-2, 5-diphenyl-tetrazolium bromide (MTT, SigmaAldrich, St. Louis, MO, USA) assay was used as described previously [13]. Briefly, BV-2 cells were plated onto 96 well plates and exposed to EA-OFP extract. MTT was added to each well then incubated for additional $2 \mathrm{~h}$ in dark at $37^{\circ} \mathrm{C}$. The medium was then aspirated from the wells and the blue formazan product obtained was dissolved in DMSO. The plates were analyzed at $570 \mathrm{~nm}$ using a microplate reader (Tecan Trading AG, Switzerland). Each experiment was conducted in triplicate. Percentage of the cell viability was calculated as (O.D. of extract treated sample/O.D. of non-treated sample) $x$ $100 \%$.

\section{Immunoblot analysis and antibodies}

Cells were washed in cold PBS three times and lysed in a buffer containing $50 \mathrm{mM}$ Tris- $\mathrm{HCl}, \mathrm{pH}$ $7.4, \quad 1 \% \quad(\mathrm{v} / \mathrm{v}) \quad \mathrm{NP}-40, \quad 0.25 \%$ sodium deoxycholate, $150 \mathrm{mM} \mathrm{NaCl}, 1 \mathrm{mM}$ EDTA, 25 $\mathrm{mM} \mathrm{NaF}, 2 \mathrm{mM} \mathrm{Na}_{3} \mathrm{VO}_{4}$ and protease inhibitor cocktail (Complete Mini ${ }^{\mathrm{TM}}$, Roche, Mannheim, Germany) at $4^{\circ} \mathrm{C}$. The lysate was clarified by centrifugation at $10,000 \mathrm{~g}$ for $20 \mathrm{~min}$ at $4^{\circ} \mathrm{C}$ to remove insoluble components. Cell lysates were normalized for protein content using BCA reagent (Pierce, Rockford, IL, USA). Equal amounts of protein were loaded onto 10\% PAGE gels and separated by standard SDS-PAGE procedure. Proteins were transferred to an NC membrane (S\&S, Dassel, Germany) and blocked with $5 \%$ non-fat dry milk in TBS. To detect protein expression, the blots were probed with the specific antibodies against iNOS and TNF- $\alpha$ followed by the secondary antibodies coupled to horseradish peroxidase (Bio-Rad, Herculus, CA, USA). The detection of $\beta$-actin with a specific antibody was used for an internal control. The immunoreactive proteins on the membrane were detected by chemiluminescence using the WestSave substrate (Lab-Frontier, Seoul, Korea) on $X$-ray film. The antibodies against iNOS, TNF- $\alpha$ and $\beta$-actin were purchased from Cell Signaling Technology INC. (Beverly, MA, USA).

\section{NO assay}

Production of NO was assayed by measuring the levels of nitrite in the culture supernatant using colorimetric assay with Griess reagent [14]. Briefly, BV-2 cells $\left(2 \times 10^{5}\right.$ cells $\left./ \mathrm{ml}\right)$ were seeded in 6-well plates in $500 \mu \mathrm{l}$ complete culture medium and treated with the OFP-EA extract at indicated concentrations for $1 \mathrm{~h}$ prior stimulation with LPS $(1 \mu \mathrm{g} / \mathrm{ml})$ for $2 \mathrm{~h}$. Culture supernatant $(50 \mu \mathrm{l})$ was reacted with an equal volume of
Griess reagent $(0.1 \%$ naphthylethylenediamine and $1 \%$ sulfanilamide in $5 \% \mathrm{H}_{3} \mathrm{PO}_{4}$ ) in 96-well plates at room temperature in the dark. Nitrite concentrations were determined by using standard solutions of sodium nitrite prepared in the culture medium. The absorbance was determined at $540 \mathrm{~nm}$ using a microplate reader (Tecan).

\section{TNF- $\alpha$ assay}

BV-2 microglia cells $\left(1 \times 10^{5}\right.$ cells/well $)$ were cultured on 96 well plates and treated with the OFP-EA extract at indicated concentrations for 1 $\mathrm{hr}$ and stimulated with LPS $(1 \mu \mathrm{g} / \mathrm{ml})$. At $4 \mathrm{hr}$ post LPS treatment, the cells were collected and the supernatants were evaluated for TNF- $\alpha$ levels using a murine TNF- $\alpha$ ELISA kit from BD Biosciences (San Jose, CA, USA) according to the manufacturer's instructions.

\section{RESULTS}

\section{Effect of OFP-EA extract on DPPH radical scavenging activity}

As shown in Fig. 1A, OFP-EA exhibited significant DPPH radical scavenging activity in a concentration-dependent manner showing a maximum effect at $200 \mu \mathrm{g} / \mathrm{ml}$ of concentration ( $p$ $<0.001)$. The ESR spectroscopy data is represented in Fig 1B.

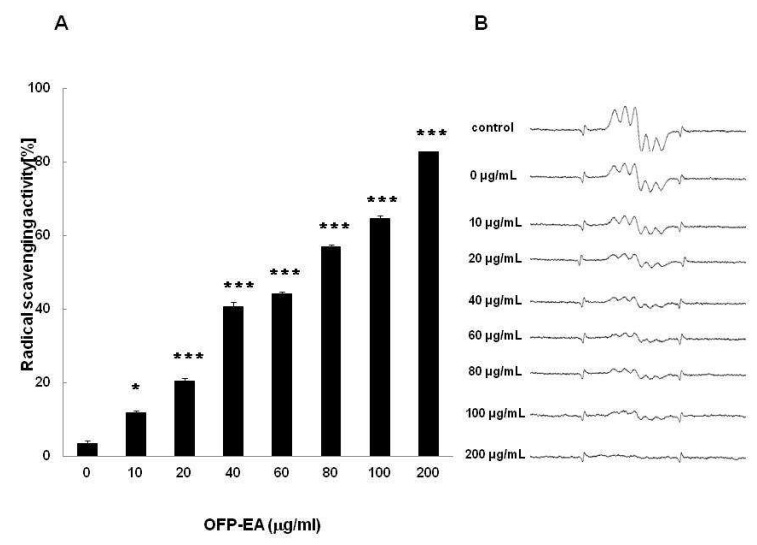

Fig 1: Effect of OFP-EA extract on DPPH radical scavenging activity. The capacities to scavenge the free radical DPPH by different concentrations of OFPEA extract $(A)$ and ESR spectra (B). BV-2 cells were treated with or without OFP-EA extract at the various concentrations $(10,20,40,60,80,100$ and 200 $\mu \mathrm{g} / \mathrm{ml})$. The scavenging activity of each sample on $\mathrm{DPPH}$ radical was measured using a JES-FA ESR spectrometer. A spin adduct was measured on an ESR spectrometer exactly $2 \mathrm{~min}$ later. Data are presented as the mean \pm S.E.M. $(n=3)$ for three independent experiments. ${ }^{*} p<0.05$ and ${ }^{* * *} p<0.001$, compared with control group by Student t-test. (OFP$E A=0 l i v e$ fruit pulp-ethyl acetate). 


\section{Effect of OFP-EA on BV-2 cell viability}

Treatment with OFP-EA at various concentrations ranging from $0.1 \mu \mathrm{g} / \mathrm{ml}$ to 100 $\mu \mathrm{g} / \mathrm{ml}$ did not affect the overall cell viability nor did they exhibit any cytotoxicity on BV2 microglia cells (Fig. 2).

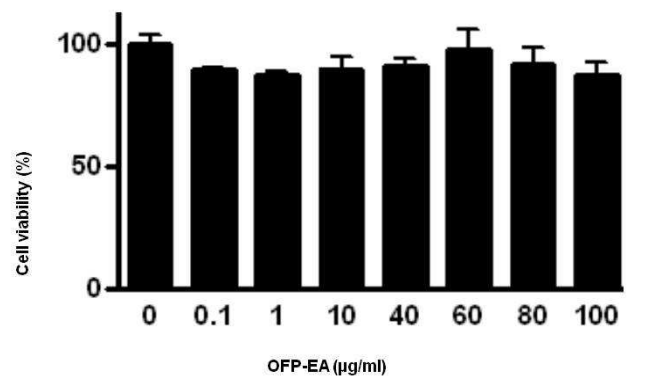

Fig 2: Effects of OFP-EA extract on the viability of BV2 microglial cells. Viability in OFP-EA extract-treated cells was determined using MTT assay in the presence or absence of LPS $(1 \mu \mathrm{g} / \mathrm{ml})$. The results are depicted as percentage of control samples. Data are presented as the mean \pm S.E.M. $(n=3)$ for three independent experiments. (OFP-EA=olive fruit pulpethyl acetate.)

\section{OFP-EA extract attenuates NO production in LPS-stimulated BV-2 cells}

Cells treated with LPS alone significantly increased in NO levels $(p<0.001)$ Fig.3. Pretreatment with OFP-EA extract significantly suppressed the LPS-stimulated increased NO release in BV-2 cells in a dose-dependent manner compared to LPS-treated cells. The maximum effect was observed at a concentration of $80 \mu \mathrm{g} / \mathrm{ml}(\mathrm{p}<0.001)$. OFP-EA extract at 10,20 and $40 \mu \mathrm{g} / \mathrm{ml}$ also significantly and concentration-dependently inhibited the release of NO in LPS-stimulated BV-2 cells.

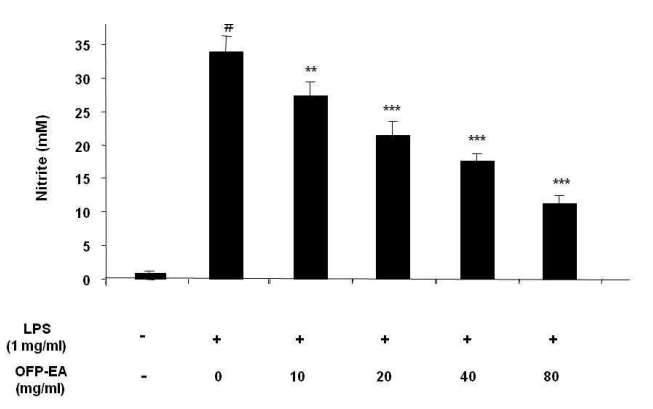

Fig 3: Effect of OFP-EA extract on NO Production in LPS-stimulated BV-2 microglial cells. BV-2 cells were treated with OFP-EA extract at various concentrations $(10,20,40$ and $80 \mu \mathrm{g} / \mathrm{ml})$ with or without LPS $(1 \mu \mathrm{g} / \mathrm{ml})$ for $4 \mathrm{hr}$. The nitrite in the culture supernatant was evaluated using Griess reagent. Data are presented as the mean \pm S.E.M. $(n=3)$ for three independent experiments. ${ }^{\#} p<0.001$, when compared with control group. ${ }^{* *} p<0.01$ and ${ }^{* * *} p<0.001$, when compared with LPS alone treated group by Student t-test. OFP$E A=o l i v e$ fruit pulp-ethyl acetate.

\section{OFP-EA extract attenuates iNOS expression in LPS-stimulated BV-2 cells}

Western blot analysis showed that the protein expression of iNOS in the LPS-stimulated BV-2 cells was also suppressed in a concentrationdependent manner (Fig 4). Although LPSstimulated BV-2 cells are associated with the increased iNOS expression, pre-treatment with OFP-EA extract suppressed the increased iNOS expression levels.

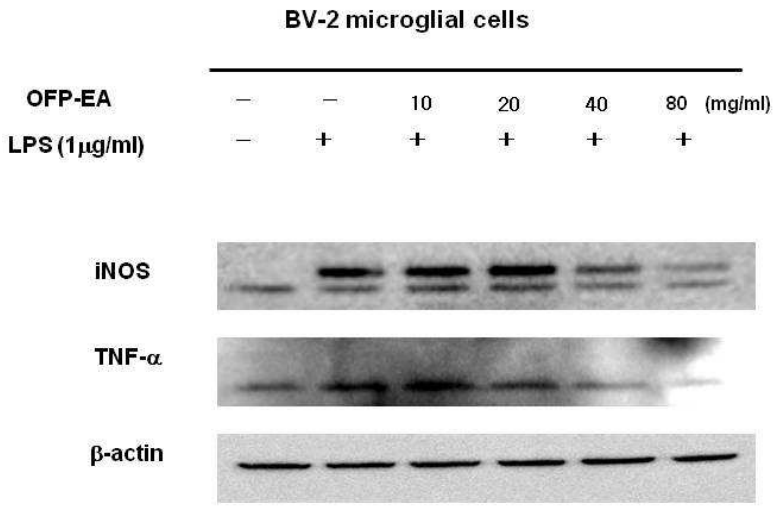

Fig 4: Effect of OFP-EA extract on iNOS and TNF-a expressional levels in LPS-stimulated BV-2 microglial cells. The expression levels of iNOS and TNF- $\alpha$ production in the LPS-stimulated BV-2 cells by various concentration of the OFP-EA extract was monitored by immunoblot analyses with the specific antibodies against iNOS and TNF- $\alpha$. The internal control used was $\beta$-actin. (OFP-EA=olive fruit pulp-ethyl acetate.)

\section{Effect of OFP-EA extract on TNF- $\alpha$ production in LPS-stimulated BV-2 cells}

As shown in Fig. 5, TNF- $\alpha$ levels increased significantly after LPS treatment when compared to those in untreated cells $(p<0.001)$. However, OFP-EA extract significantly inhibited TNF- $\alpha$ production significantly in a concentrationdependent manner $(p<0.01$ at $10 \mu \mathrm{g} / \mathrm{ml}$ and $\mathrm{p}<0.001$ at 20,40 and $80 \mu \mathrm{g} / \mathrm{ml}$, respectively).

\section{DISCUSSION}

In the present study we report that the ethyl acetate fraction of olive fruit pulp extract significantly inhibited production of NO, suppressed the expression of iNOS protein level and attenuated the increased TNF- $\alpha$ production and protein expression in LPS-simulated BV-2 microglial cells. Further the OFP-EA extract exhibited significant antioxidant activity evaluated by DPPH free radical scavenging method.

It is widely believed that free radicals and reactive oxygen species (ROS) are important causative factors in the development of age- 


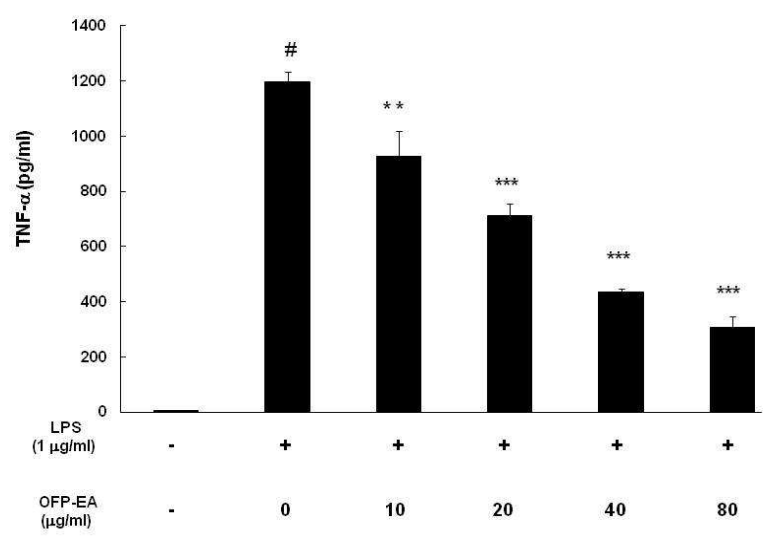

Fig 5: Effect of OFP-EA extract on TNF- $\alpha$ production in LPS-stimulated BV-2 microglial cells. Suppression of pro-inflammatory cytokine TNF- $\alpha$ expression by OFP-EA extract was measured with ELISA test. BV-2 cells were treated with OFP-EA extract at 10, 20, 40 and $80 \mu \mathrm{g} / \mathrm{ml}$ with or without LPS $(1 \mu \mathrm{g} / \mathrm{ml})$ for $4 \mathrm{~h}$. The TNF- $\alpha$ in the culture supernatant was evaluated using a murine TNF- $\alpha$ ELISA kit. Data are presented as the mean \pm S.E.M. $(n=3)$ for three independent experiments. ${ }^{\#} p<0.001$, when compared with control group. ${ }^{* *} p<0.01$ and ${ }^{* * *} p<0.001$, when compared with LPS alone group by Student t-test. (OFP$E A=o l i v e$ fruit pulp-ethyl acetate.)

related neuro-inflammatory and neurodegenerative diseases by stimulating release of cytokines which are responsible for the recruitment of additional neutrophils and macrophages [15]. Thus free radicals are important mediators that provoke or sustain inflammatory responses and their neutralization by antioxidants and radical scavengers can reduce neuro-inflammation. It was well known that DPPH radical assay as one of the widely used methods for evaluating the free radical scavenging activities of several antioxidants in a relatively short period of time [12].

Earlier studies revealed that olive oil phenols possessed strong antioxidant compounds [16]. In our present study, the ethyl acetate fraction obtained from the olive fruit pulp extract also exhibited significant free radical scavenging effect indicating that the fruit pulp extract might contain potential antioxidant agents.

Previous studies on tumor cell lines in vitro and animal models in vivo revealed that the olive oil and leaf extracts might be helpful in suppressing inflammatory conditions [9, 10]. The phenolic antioxidant compounds present in Olive oil extracts were also reported to show antiinflammatory properties [17]. In light of such reports that antioxidants can reduce neuroinflammation, we used OFP-EA extract to evaluate for its anti-neuroinflammatory activity in LPS-stimulated BV-2 microglial cells.

A significant number of reports have established that inflammatory mediators, including $\mathrm{NO}$ and iNOS are responsible for the symptoms of many neuro-inflammatory diseases [18,19]. Neuroinflammatory response is indicated by activated microglia producing elevated levels of proinflammatory cytokines [1,2]. Thus, inhibition of cytokine production or function serves as a key mechanism in the control of inflammatory responses in neuro-degeneration. The present results from our study suggest that the OFP-EA extract significantly inhibited the increased NO production and iNOS protein expression in LPSstimulated BV-2 cells.

TNF- $\alpha$, an inflammatory cytokine, mainly produced by activated macrophages is involved in systemic inflammation that stimulate the acute phase reaction. TNF- $\alpha$, not only amplifies the inflammatory cascade, but also causes the inflammatory injury [20,21]. TNF- $\alpha$ expression are up-regulated in the brains of patients with neuro-degenerative diseases such as $A D$ and PD suggesting a causative role in neurodegenerative disorders [22,23]. Microglial cell activation by LPS produces various cytokines, such as IL-6, and TNF-a, leading to the attraction of neutrophils and the accumulation of neutrophil-secreted proteases and reactive oxygen species (ROS) at the site of inflammation. From our results, it appears that OFP-EA may act by suppressing the expression of TNF- $\alpha$ at transcriptional (data not shown) and protein levels and thereby inhibiting NO production and iNOS expression levels in LPSstimulated BV-2 cells.

\section{CONCLUSION}

This study demonstrates that OFP-EA plays a role in mitigating neuro-inflammatory responses in LPS-stimulated BV-2 microglial cells. The OFP-EA extract also showed potent antioxidant effects. Earlier reports on the pharmacological benefits of olives including anti-inflammatory, bacteriocidal and bacteriostatic activities were attributed mainly to their polyphenolic compounds such as hydroxytyrosol and tyrosol. In particular, hydroxytyrosol was found in great quantities in the remains from fruit oil processing, such as pomace olive oil, olive-mill waste water and rinse waters $[24,25]$. The phenolic compounds present in olive fruit pulps might be responsible in exhibiting such potent antioxidant and anti-neuroinflammatory effects. 


\section{COMPETING INTEREST}

The authors declare that there are no conflicts of interest.

\section{ACKNOWLEDGEMENT}

This research was supported by a grant from the Regional Strategic Planning Technology Development Program funded by the Ministry of Knowledge Economy of the Korean government and by a grant from Macrocare Tech., Ltd. The authors thank Chungbuk Technopark for excellent administrative assistance.

\section{REFERENCES}

1. Matsumoto $Y$, Ohmori $K$, Fujiwara $M$. Immune regulation by brain cells in the central nervous system: microglia but not astrocytes present myelin basic protein to encephalitogenic $T$ cells under in vivomimicking conditions. Immunol 1992; 76: 209-216.

2. Gao HM, Jiang J, Wilson B, Zhang W, Hong JS, Liu B. Microglial activation-mediated delayed and progressive degeneration of rat nigral dopaminergic neurons: relevance to Parkinson's disease. J Neurochem 2002; 81: 1285-1297.

3. Nelson PT, Soma LA, Lavi E. Microglia in diseases of the central nervous system. Annal Med 2002; 34: 491500.

4. Liu B, Hong J., Role of microglia in inflammation-mediated neurodegenerative diseases: mechanisms and strategies for therapeutic intervention. J Pharmacol Exp Therap 2003; 304: 1-7.

5. Eikelenboom $P$, van Gool WA, Neuroinflammatory perspectives on the two faces of Alzheimer's disease. J Neural Transm 2004;111:281-294.

6. Dawson MR, Dobbs A, Hooper HR, McEwan AJ, Triscott J, Cooney J. Artificial neural networks that use singlephoton emission tomography to identify patients with probable Alzheimer's disease. Euro J Nucl Med 1994.21: 1303-1311.

7. Kiritsakis $A$. Olive oil- $2^{\text {nd }}$ edition, From the tree to the table. Food and Nutrition. Press, Inc., Trumbull, Connecticut, USA, 1998.

8. Cook NC, Samman S. Flavonoids- chemistry, metabolism, cardioprotective effects, and dietary sources. Nutr Biochem 1996; 7: 66- 76 .

9. Covas MI. Bioactive effects of olive oil phenolic compounds in humans: reduction of heart disease factors and oxidative damage. Inflammopharmacol 2008; 16:216-8.

10. Rosignoli $P$, Fuccelli $R$, Fabiani $R$, Servili M, Morozzi G. Effect of olive oil phenols on the production of inflammatory mediators in freshly isolated human monocytes. J Nutr Biochem 2013. http://dx.doi. org/10.1016/j.jnutbio.2012.12.011.

11. Caponio F, Alloggio V, Gomes T. Phenolic Compounds of Virgin Olive Oil: Influence of Paste Preparation Techniques. Food Chem 1999; 64: 203-209.

12. Sanches-Moreno $C$, Plaza $L$, Ancos B, Cano MP. Nutritional characterization of commercial trnaditional pasteurized tomato juices: carotenoids, vitamin and radical-scavenging activity. Food Chem 2006; 98: 749-756.

13. Tang YJ, Yang JS, Lin CF, Shyu WC, Tsuzuki M, Lu CC, Chen YF, Lai KC. Houttuynia cordata Thumb extract induces apoptosis through mitochondrialdependent pathway in HT-29 human colon adenocarcinoma cells. Oncol Rep 2009; 22: 10511056.

14. Green LC, Wagner DA, Glogowski J, Skipper PL, Wishnok JS, Tannenbaum SR. Analysis of nitrate, nitrite, and $\left[{ }^{15} \mathrm{~N}\right]$ nitrite in biological fluids. Anal Biochem. 1982; 126: 131-138.

15. Finkel T, Holbrook NJ. Oxidants, oxidative stress and the biology of ageing. Nature 2000; 408: 239-247.

16. Raederstorff $D$. Antioxidant activity of olive polyphenols in humans: a review. Int J Vitam Nutr Res 2009; 79: 152-65.

17. Lucas L, Russell A, Keast R. Molecular mechanisms of inflammation. Antiinflammatory benefits of virgin olive oil and the phenolic compound oleocanthal. Curr Pharm Des 2011; 17:754-68.

18. Tuttolomondo A, Di Raimondo $D$, di Sciacca $R$, Pinto $A$, Licata $G$. Inflammatory cytokines in acute ischemic stroke. Curr Pharm Des. 2008; 14: 3574-3589.

19. Merrill JE, Benveniste EN. Cytokines in inflammatory brain lesions: helpful and harmful. Trends Neurosci. 1996; 19: 331-338.

20. Esposito E, Cuzzocrea S. TNF-alpha as a therapeutic target in inflammatory diseases, ischemiareperfusion injury and trauma. Curr Med Chem. 2009; 16(24): 3152-3167.

21. Frankola KA, Greig NH, Luo W, Tweedie D. Targeting TNF-alpha to elucidate and ameliorate neuroinflammation in neurodegenerative diseases. CNS Neurol Disord Drug Targets 2011; 10: 391 403.

22. Perry RT, Collins JS, Wiener H, Acton R, Go R.C. The role of TNF and its receptors in Alzheimer's disease. Neurobiol. Aging 2001; 22: 873-883.

23. Nagatsu $T$, Sawada $M$. Inflammatory process in Parkinson's disease: Role for cytokines. Curr Pharm Des 2005; 11: 999-1016.

24. Yang DP, Kong DX, Zhang HY. Multiple pharmacological effects of olive oil phenols. Food Chem 2007; 104: 1269-1271.

25. Henn A, Lund S, Hedtjarn M, Schrattenholz A, Porzgen P, Leist $M$. The suitability of BV2 cells as alternative model system for primary microglia cultures or for animal experiments examining brain inflammation. Altex 2009; 26: 83-94. 